\title{
Fractographic Examination of the Vertical Stabilizer and Rudder from American Airlines Flight 587
}

\author{
Matthew R. Fox ${ }^{*}$ and Carl R. Schultheisz ${ }^{\dagger}$ \\ National Transportation Safety Board, Washington D.C. \\ James R. Reeder ${ }^{*}$ \\ NASA Langley Research Center, Hampton, VA 23681
}

\begin{abstract}
The first major structural component failure of a composite part on a commercial airplane occurred during the crash of American Airlines Flight 587. The fractured composite lugs that attached the vertical stabilizer to the aircraft tail and the fractured composite honeycomb rudder were examined as part of the National Transportation Safety Board investigation of the accident. In this paper the composite fractures are described and the resulting clues to the failure events are discussed.
\end{abstract}

\section{Introduction}

On November 12, 2001, shortly after taking off from Kennedy International Airport, the composite vertical stabilizer and rudder separated from the fuselage of American Airlines Flight 587, rendering the airplane uncontrollable. The Airbus A300-600 airplane crashed into a neighborhood in Belle Harbor, New York, killing all 260 persons aboard the airplane and 5 persons on the ground. This accident was unique partly in that it was the first time a major structural component fabricated out of composite material failed in flight on a commercial airplane.

Analysis of the flight data recorder revealed the airplane had performed a series of yawing maneuvers in the seconds before separation of the vertical stabilizer, and the separation of the vertical stabilizer occurred while the airplane was pointed to the left of its flight path. This orientation would have produced a bending moment on the vertical stabilizer leading to tension on the right-side attachments and compression on the left.

The separated pieces of the vertical stabilizer and rudder were recovered away from the main crash site mainly from the water of Jamaica Bay. The vertical stabilizer was largely intact, and had separated from the fuselage by fractures at the lower end where it had attached to the fuselage. Many fractured pieces of the rudder were recovered near, but mostly fractured from, the vertical stabilizer. As part of the overall investigation into the accident, a detailed examination of the fractures in the vertical stabilizer and rudder was conducted in order to determine the failure mechanism and direction of fracture propagation where possible, including assessing the possibility of any pre-existing damage or fatigue cracking.

In addition, three subcomponent tests were conducted on aft lugs from an unused skin panel and from another airplane using accident loads derived from analysis of recorded flight data. Fracture patterns for these three test specimens were compared to the corresponding structure on the accident airplane.

In this paper, the structures of the vertical stabilizer and rudder are described. Next, results of the fractography of the vertical stabilizer and rudder are presented and the interpretation of the results toward understanding the failure is discussed. Finally, fractographic examination results of the three subcomponent tests are presented and significance of the fracture features are discussed.

\section{Description of Structures}

Development of the Airbus A300-600 model began in 1980, and certification occurred in 1984. The vertical stabilizer and rudder for the accident airplane, delivered new in 1988, had a symmetric airfoil shape. The vertical stabilizer and rudder were 27 feet 3 inches tall. From leading edge to trailing edge the width of the vertical stabilizer and rudder was 25 feet at the base and 10 feet 2 inches at the tip.

\footnotetext{
*Senior Materials Engineer, Materials Laboratory Division

${ }^{\dagger}$ Materials Research Engineer, Materials Laboratory Division

${ }^{\dagger}$ Research Engineer, Mechanics of Structures and Materials Branch.
} 


\section{A. Vertical Stabilizer Structure}

The vertical stabilizer for the Airbus A300-600 airplane was a stiffened box with removable leading edge fairings and trailing edge panels. An internal view drawing of the vertical stabilizer is shown in Figure 1. The stiffened box consisted of two integrally stiffened skin panels for the left and right sides, spars for the forward and aft sides, and closure ribs at the upper and lower ends. The integral stiffeners in the skin panels consisted of 24 "I"shaped stringers that extended spanwise parallel to the aft spar, numbered from the aft to forward. Internal stiffeners for the box consisted of a center spar at the lower end of the span and 16 ribs, not including the two closure ribs. The ribs were numbered from the lower end upward starting with the lower closure rib. The components of the box were riveted together, and the leading edge fairings and trailing edge panels were attached with threaded fasteners.

Except for the fasteners, lightning protection strips, and trailing edge panel support frames, the vertical stabilizer was made entirely of composite materials. The stiffened box of the vertical stabilizer was a solid carbon-fiber reinforced polymer (CFRP) laminate composed of T300 carbon fibers in a CIBA 913 epoxy matrix. The laminate included both unidirectional tape and eight-harness satin fabric layers in the construction. The zero-degree fibers of the fabric and tape layers in the composite were oriented parallel to the stringers and aft spar, which was at an angle of 33.3 degrees aft of vertical. The leading edge fairings and the trailing edge panels for the vertical stabilizer were sandwich composites having a Nomex honeycomb core and glass-fiber reinforced polymer (GFRP) facesheets on the leading edge fairings and both GFRP and CFRP facesheets for the trailing edge panels.

The main attachment locations for the vertical stabilizer were six CFRP lugs (main lugs) that connected by bolts approximately 2 inches in diameter to six metal clevis fittings on the fuselage. A schematic view of the typical assembly cross-section is shown in Figure 2 (drawing of lug cross-section). After the assembly was cured, the lug attachment bolt holes were core-drilled out. Three main lugs extended from the lower end of each of the two vertical stabilizer skin panels. At the thickest point, the main lugs were approximately 1.62 inches, 2.48 inches, and 2.17 inches thick for the forward, center, and aft lugs, respectively. The aft lugs alone each had more than 170 layers composed of approximately 50 percent \pm 45 -degree fabric, 25 percent $0 / 90$-degree fabric, and 25 percent 0 -degree tape. The thickness of each lug decreased as plies were dropped in the lug-to-skin transition area. The skin layers were made of \pm 45 -degree fabric. The I-shaped stiffeners had 0 degree tape at the caps and \pm 45 -degree fabric in the web.

Each lug contained two separate pieces that were cured separately before the final assembly. In the final assembly, the outer precured half was laid down, followed by the skin layers, then the inner precured half, the compensation layers, the rib 1 attach flange, the stringer inner flange (tape) layers, and the stringer module layers.

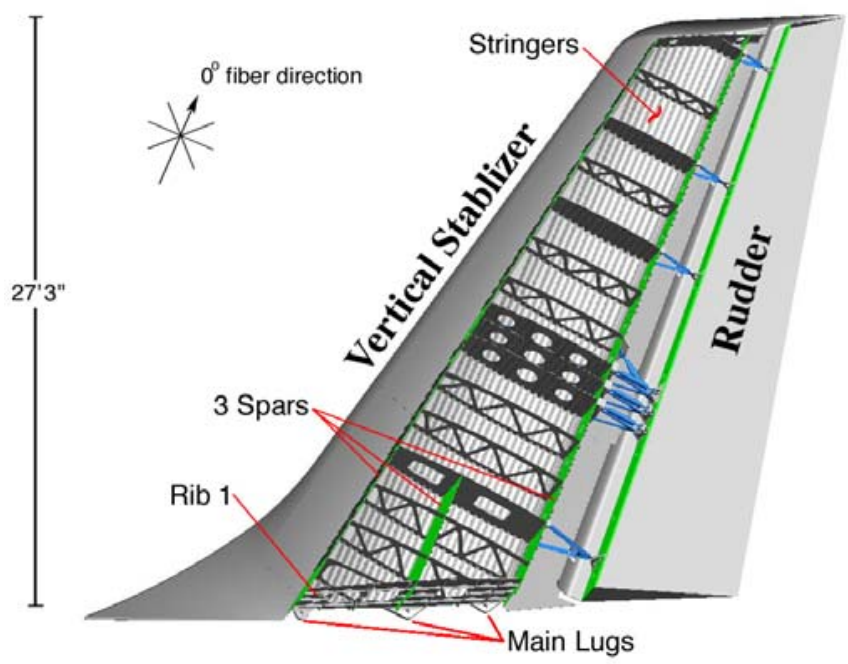

Figure 1. Airbus A300-600 vertical stabilizer construction.

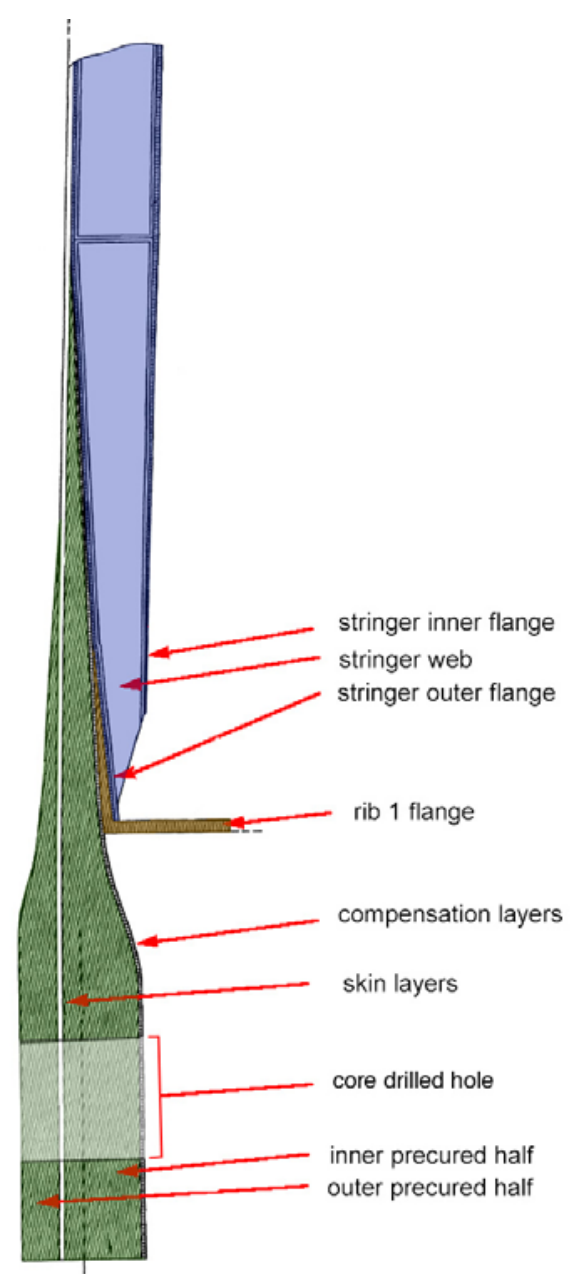

Figure 2. Drawing of main lug cross-section. 
Six smaller composite lugs (transverse lugs) attached the vertical stabilizer to the fuselage by lateral yokes. Two of these transverse lugs extended from the lower end of each of the three spar webs. These lugs were approximately 0.47 inch thick.

\section{B. Rudder Structure}

The rudder was a single-segment wedge-shaped box design with removable leading edge fairings. The wedge consisted of left and right skin panels with a single spar at the forward side. The skin panels were fastened together at the trailing edge by rivets with a metallic strip on each side. Threaded through-bolts near the trailing edge also helped fasten the two skin panels. At the lower end, a metal strap, which retained the rubber lower sealing strip, was attached by threaded fasteners that also connected the skin panels to the lower rib. The spar was riveted to the skin panels. Pieces of the leading edge fairings were attached to the skin panels with threaded fasteners and to each other with threaded fasteners through metal support flanges. There were no internal stiffeners in the wedge. Closure ribs cap the upper and lower ends of the rudder.

The rudder skin panels and spar were sandwich composite panels. Each panel had a Nomex honeycomb core and GFRP and CFRP face sheets. The leading edge fairings were sandwich composites with GFRP facesheets.

The rudder was attached to the vertical stabilizer by seven hinges, numbered from the lower end upward. There were three rudder position actuators that control the rotation of hinges 2, 3, and 4. Each hinge was composed of two aluminum alloy fittings pinned together at the hinge line. The forward fittings were attached to the vertical stabilizer with bolts that fastened to CFRP flanges on the vertical stabilizer aft spar. Spherical bearings were located at each attach point for the forward fitting. The aft fittings were attached to the rudder spar using bolts that threaded into barrel nuts located in fiberglass blocks embedded in the rudder skin panels aft of the rudder spar.

\section{Fractographic Examination Procedures and Challenges}

For most common airplane structural metals, visual inspection or low-power magnification is often sufficient to determine fracture mechanism and direction. For metals, the fracture plane, surface roughness, radial marks, chevrons, shear lips, and general deformation when present all provide macroscopic clues to the fracture mechanisms, direction of fracture propagation, and relative motion of mating surfaces. Preexisting cracks in metals often show staining or changes in color associated with corrosion ${ }^{1}$. Using these clues, large areas of damaged structure can be examined relatively quickly by an experienced investigator to identify fracture origins and areas requiring closer inspection.

The fractographic examination of the composite fractures in the accident vertical stabilizer presented a challenge in that it was more extensive than what is typically required for an overstress fracture of a similar metal structure. Visual clues to preexisting fractures, such as flat fracture features with curving boundaries or staining from corrosion that can be readily observed in structural metals, generally are not readily visible in composites. Furthermore, the visual cues to fracture propagation directions that are sometimes apparent in composite structures, such as crack branching in translaminar fractures (fractures that break fibers) or banding in delaminations (fractures between layers), were not apparent in many of the fractures of interest. In determining the failure mechanism and directions in the vertical stabilizer and rudder during the accident investigation, fine fracture features were examined at high magnification across relatively large areas of the fracture surfaces in order to determine fracture mechanisms and propagation directions, a time-consuming process for the failure investigation. However, since fatigue fractures and other preexisting cracks may appear similar during a macroscopic examination, the detailed inspection using high magnification was required to complete the fractographic analysis.

The fractographic examination of the translaminar fractures and delaminations of the vertical stabilizer and rudder incorporated visual examination and scanning electron microscopy (SEM). The visual examination included the documentation of the macroscopic fracture features. The documentation included mapping of fractures, which could be used to aid in identifying fracture propagation directions from crack branching patterns. Also, macroscopic indications of translaminar fracture under tension or compression were documented. On delaminations, surfaces were examined for changes in reflectivity, which could indicate changes in fracture mechanism or mode ${ }^{2}$. However, for most of the fracture surfaces, SEM was required to determine the fracture mechanism and fracture propagation direction.

SEM examination of translaminar fracture surfaces was used to determine the fracture mechanism and propagation directions, and SEM examination of delamination surfaces was used to identify the layers involved, fracture mechanisms, modes of fracture, and propagation directions. Additionally, results of the examination were 
used to check the construction against the manufacturing drawings and to determine how the fractures related to the loading of the overall structure.

Over 300 SEM photographs were taken of translaminar fractures in the main attachment areas of the vertical stabilizer, and more than 150 square inches of delamination surface areas were examined at high magnification. Examined fracture surfaces were coated with a conductive layer of gold and palladium. For translaminar fractures intersecting the lug attachment hole, the entire fracture surfaces were examined at high magnification, and for translaminar fractures above the lug holes, several inches of the fracture were examined at high magnification. Samples for the SEM examination of the delamination surfaces were typically approximately two inches square and were taken from widely spaced areas on the exposed fracture surfaces in an effort to identify the overall trends. Samples were also taken across areas where the delamination surface morphology changed (mostly as a result of the ends of plies in the lay-up) to explore for local differences in stress state or crack propagation direction. Two samples, one from each of the two large delaminations, were not cleaned and were the first ones examined in order to explore the surface for matrix rollers, which would have been an indication of fatigue ${ }^{3}$. Since uncleaned samples were covered in debris, all other fracture surfaces were ultrasonically cleaned in water before coating.

Another challenge for the fractographic analysis was the relatively small amount of fractographic reference material dealing specifically with fabric-reinforced composites. Most of the literature describing fractography of composites focused on unidirectional tape lay-ups. However, fabrics have unique characteristics that lead to features such as more variation in resin content on delamination surfaces and less fiber pullout in translaminar fractures relative to tape-reinforced materials. The presence of woven fabric in the construction led to some interesting phenomena that could be useful in better analyzing composites failures. In the unidirectional lay-ups, river marks were typically only observed in Mode I loading. However, in the fabric construction, river marks also could be found in matrix-rich areas in the vicinity of the bundle crossings, and could be seen in the base of hackles in the transition from a bundle at one orientation to a perpendicular crossing bundle. The river marks in the matrixrich bundle crossings were used to identify a general direction of fracture propagation upward and aftward for both of the large delaminations (at the forward left and aft left attachments). The use of the river marks at the base of the hackles was explored in the examination of the delaminations at the forward right lug. As composites with fabric reinforcements are being increasingly used in airplane structures, more research is needed in characterizing these fracture surfaces generated under controlled laboratory conditions to assist the failure analyst in interpreting fractographic details.

\section{Fracture Surface Observations and Discussion}

\section{A. Stabilizer Damage}

The vertical stabilizer was largely intact with no significant areas of skin buckling. An overall view of the vertical stabilizer as it was being recovered from the water of Jamaica Bay is shown in Figure 3. At the lower end, each of the six attachment locations were separated either by fractures that intersected the lug attach hole or by fractures through the structure above the hole. A schematic drawing of the lower end of the vertical stabilizer is shown in Figure 4, where a general fracture location for each lug is shown with overall views of each of these lug fractures. Portions of rib 1, the rib 1 rib-to-skin attach angle, and the lower end of the forward spar also were fractured. Along the trailing edge, the trailing edge panels were damaged in several locations. A more detailed description of the damage is presented in reference 4 .

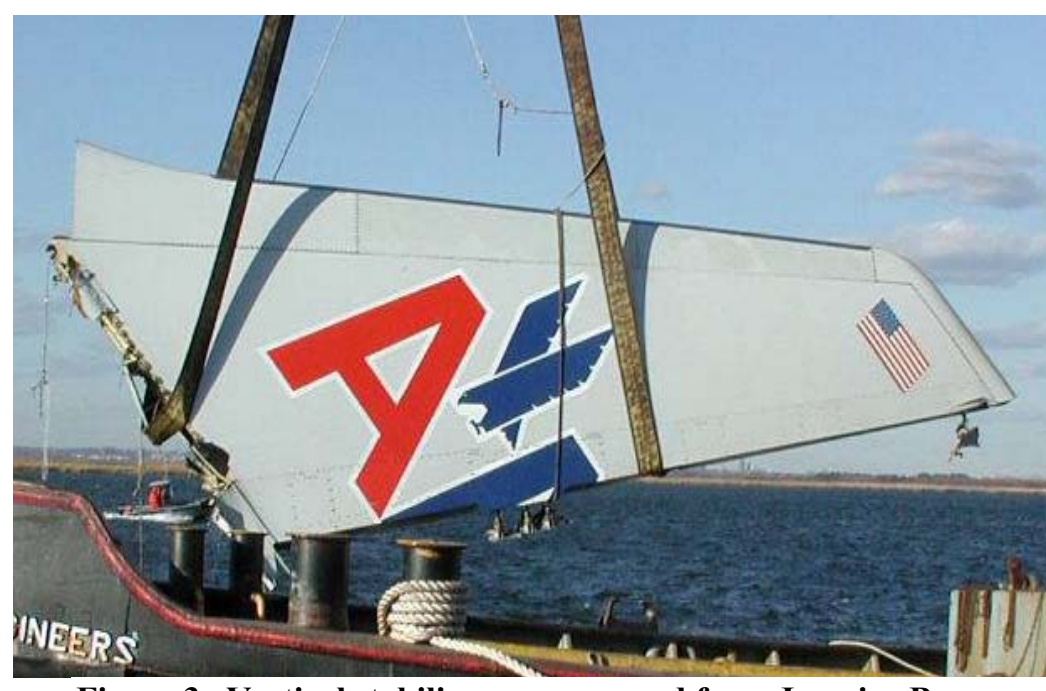

Figure 3. Vertical stabilizer as recovered from Jamaica Bay. 


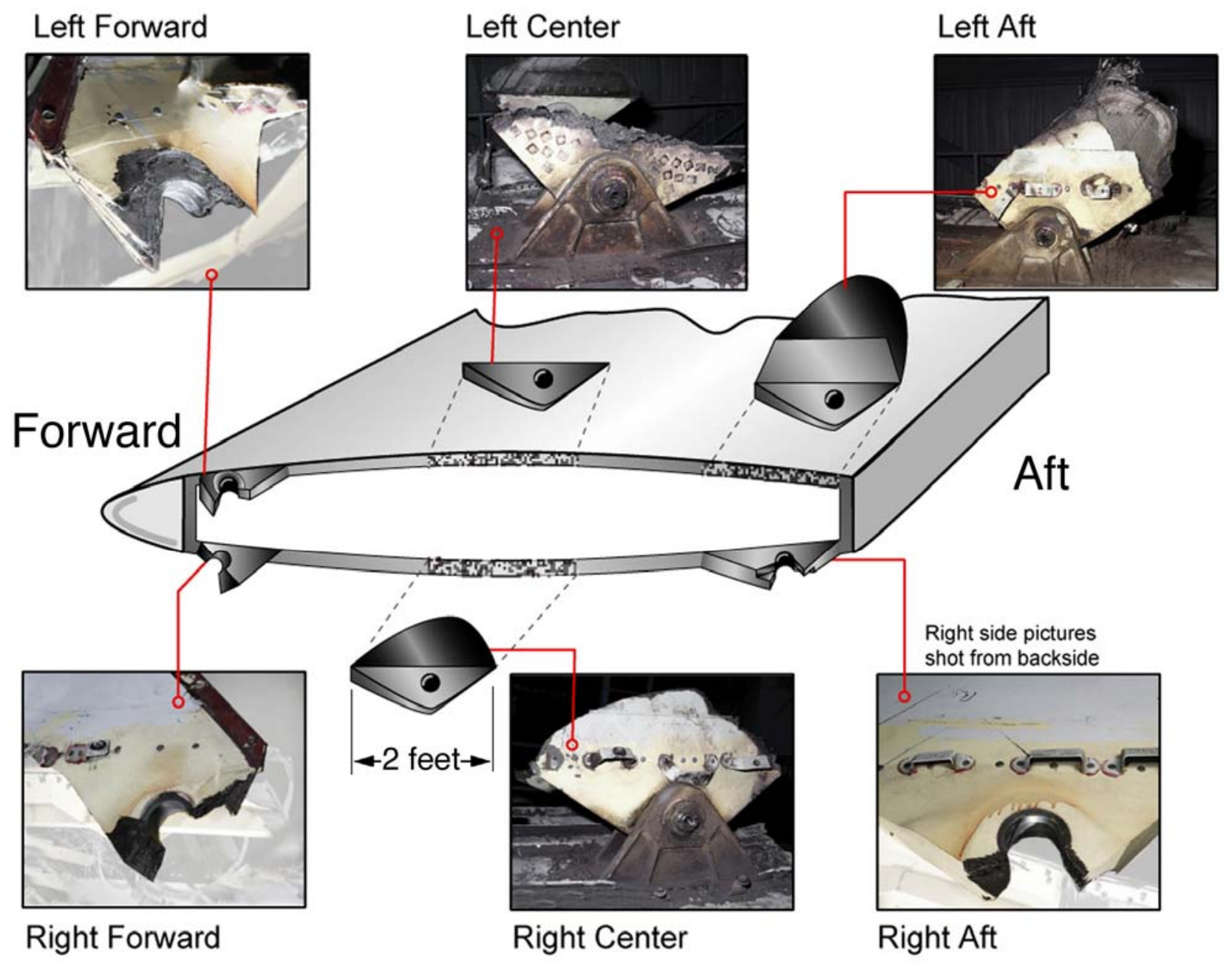

Figure 4. Overall views of main lug fractures with relative locations on vertical stabilizer.

\section{B. Description of main lug fractures}

The right aft, right forward, and left forward main lugs had translaminar fractures that intersected the attachment hole, and the remaining lugs had translaminar fractures in the structure above the lug. Each of the lugs had delaminations in the lug area and/or in the structure above the lug. Details of the fractographic examination are presented in references 5 and 6 . Some of the delaminations extended into the main portion of the vertical stabilizer, and the extents of these delaminations were determined using nondestructive inspection (NDI), including ultrasonic inspection and x-ray-computed tomography scanning and imaging. Results of the NDI of the vertical stabilizer are presented in references 7 and 8 .

\section{Macroscopic fracture features}

The main lug translaminar fractures on the right side of the vertical stabilizer generally had rough fracture features consistent with overstress fracture in primarily tensile loading. Delaminations were observed at the edges of each of the lugs on the right side. The extent of the delaminations as determined using NDI was limited to within the fractured lugs or within approximately four inches of a translaminar fracture.

The right aft lug failed by translaminar fracture through the bolt hole as shown in Figure 5. The translaminar fracture surfaces had a rough appearance consistent with fracture primarily under tensile loading. Fractures on each leg of the lug were on different translaminar planes, and the change in planes occurred near the center of the lug thickness. On the aft side of the bolt hole, the outboard side of the fracture was in a plane nearly perpendicular to the zero-degree fiber direction, and the inboard side of the fracture was in a plane approximately parallel to the 45degree fiber direction. On the forward side of the bolt hole, the outboard side of the fracture was in a plane approximately parallel to the zero-degree fiber direction, and the inboard side of the fracture was in a plane nearly 


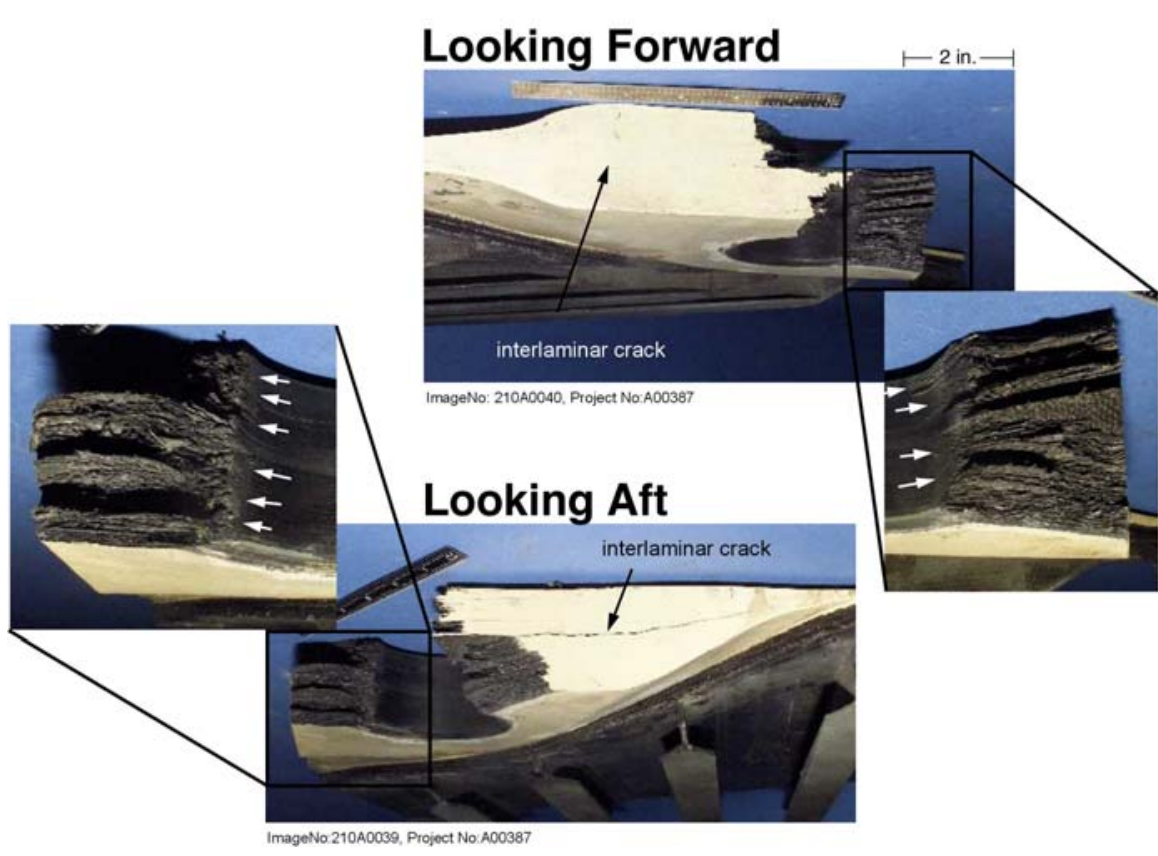

Figure 5. Right aft lug translaminar fractures (pictured from below the lug). parallel to rib 1. Bearing damage was observed at the bore surface near both fracture surfaces, as indicated by white unlabeled arrows in Figure 5.

The right center lug failed above the bolt hole in the lugto skin transition above rib 1. Translaminar fracture features were relatively rough, consistent with overstress fracture under tensile loading.

Fractures on the right forward lug intersected the lug hole. Translaminar fracture features were relatively rough, consistent with overstress fracture under tensile loading. Some evidence of local compressive loading was observed near the aft side of the lug, indicating that fracture occurred at the forward side first, and then the lower ligament hinged about the aft side.

The main lug translaminar fractures on the left side of the vertical stabilizer also generally had rough fracture features consistent with overstress fracture in primarily tensile loading, but they also showed indications of bending to the left. The left forward lug had multiple delaminations in the lug area and an impression on the left side corresponding to contact with the fuselage attachment clevis. The impression indicates the left skin panel of the vertical stabilizer bent to the left and in order to obtain the bending displacement required, the right side skin panel must have separated from the fuselage first. The left forward lug also had a delamination extending upward into the structure up to 43 inches from the lower end. The left center lug had an area with compression fracture features at the outboard side of the translaminar fracture, consistent with bending loads to the left. The left aft lug had delaminations extending up to 37 inches from the lower end. Multiple delaminations through the thickness were present in the lugto-skin transition area, allowing layers associated with lug to separate from the rest of the structure.

\section{Microscopic fracture features}

On translaminar fractures, the ends of some fibers were oriented roughly perpendicular to the fracture plane. A typical SEM view of these fiber ends on one of the translaminar fracture surfaces is shown in Figure 6. Fiber ends such as those shown in Figure 6 were examined using SEM to help determine the fracture mechanism and propagation direction. For fibers having radial patterns indicative of tensile fracture, the local fracture propagation direction could be determined from the direction of the radial pattern of several fibers ${ }^{9,10}$. Then, general directions of fracture propagation for the translaminar fractures could be determined by averaging the directions indicated by the

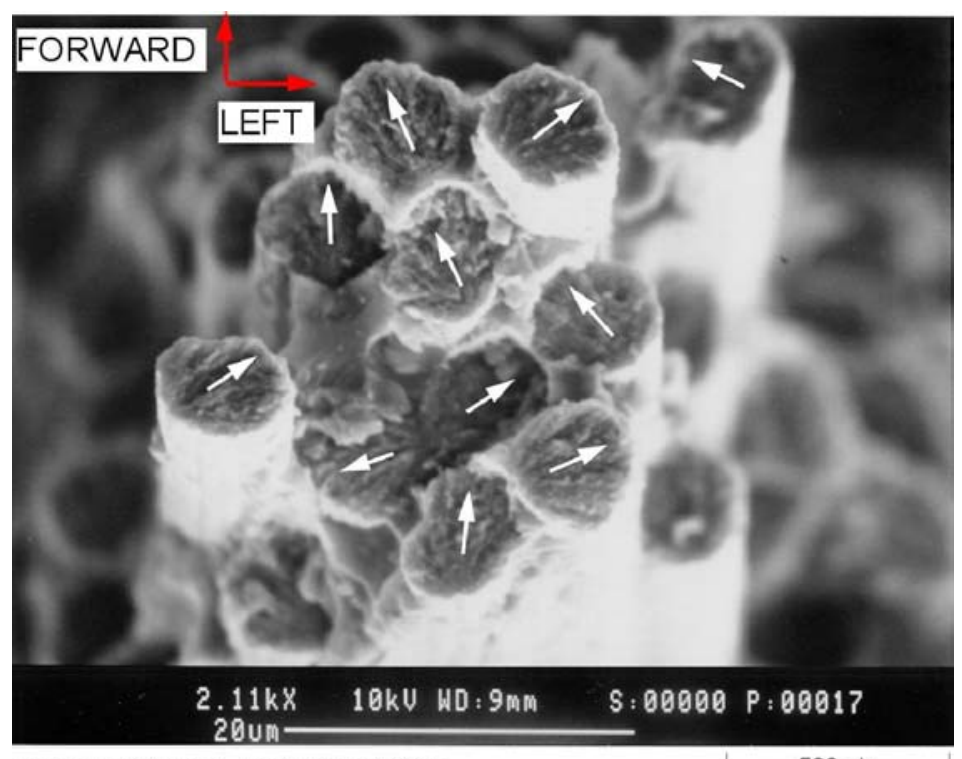

ImageNo:210A0051, Project No:A00387

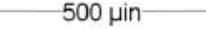

Figure 6. Fractured carbon fibers showing crack growth directions. 


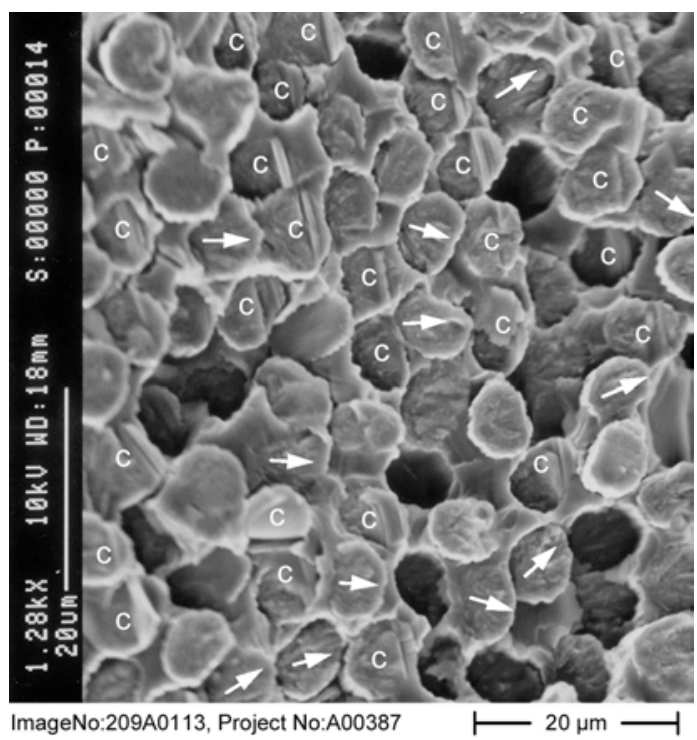

Figure 7. Fractured carbon fibers showing compression chop marks (C). radial patterns across many areas of the fracture surfaces. Also, since fatigue and overstress fractures can appear similar from a macroscopic view, the microscopic examination of the fracture surfaces included looking for evidence of fatigue such as rounded edges on fiber ends ${ }^{11}$ or striations in the matrix ${ }^{3,10,12}$, however, no evidence of fatigue was observed on any of the translaminar fracture surfaces.

At high magnification, fiber end fractures for fibers oriented perpendicular to the fracture plane generally showed radial fracture features consistent with fracture under tensile loading. In an area near the outboard surface of the left center lug, fiber ends showed chop marks (lines across the fiber ends), indicative of local compressive loading. Examples of these chop marks can be seen in Figure 7 on the fiber ends marked with a "C". The combination of tension on the inside edge and compression on the outboard surface is associated with an overall lug bending to the left. Using the radial patterns on the lug translaminar fractures, fracture propagation directions were determined to be extending from the lug holes for the right aft, right forward, and left forward lugs (all lugs that had fractures intersecting the lug hole). For the right center lug, fracture propagated from aft to forward, and for the left center and left aft lugs, fracture propagated from forward to aft.

Samples of the delamination fracture surfaces were examined in the scanning electron microscope to determine the orientation of the shear stress at the fracture and to identify the direction of crack propagation. Fracture features that were used to make these determinations included hackles (thin plates of fractured matrix material between fibers oriented perpendicular to the fiber axis, with free edges that point in a general direction opposite to the local shear applied at the fracture surface) $)^{13,14}$ and river marks (related to the initiation of matrix cracks that coalescence into larger cracks, indicating the direction of propagation) $)^{2}$. A typical view of hackles and river marks observed on one of the delaminations is shown in Figure 8. The samples also were carefully examined for indications of fatigue crack propagation, such as striations in the fiber impressions in the matrix ${ }^{3,10}$, matrix rollers (pieces of fractured matrix material rolled into cylindrical shapes by the relative motion of the fracture surface during cyclic loading) ${ }^{3,10}$, or rubbed hackle formations ${ }^{3}$, however no evidence of fatigue was observed on any of the delamination surfaces.

When hackles form in CFRP's, the hackles orient perpendicular to the fiber axes, so the hackles in the orthogonal bundles of the woven fabric would generally point in two orthogonal directions. In some cases, the superimposed imprints of unidirectional tape at $45^{\circ}$ to those bundles also added hackles at a third direction. Hackles also point generally opposite the locally applied shear at the fracture surface, so the multiple orientations of hackles from the different fiber bundles bound the direction of the local shear within an angle of $90^{\circ}$.

River marks were observed in matrix-rich areas in the vicinity of the bundle crossings, and could be seen in the base of hackles in the transition from a bundle at one orientation to a perpendicular crossing bundle. The river marks in the matrix-rich bundle crossings were used to identify a general direction of fracture propagation upward and aftward for both of the large delaminations (at the forward left and aft left attachments). The use of the river marks at the base of the hackles to determine delamination growth direction was explored in the examination of the delaminations at the forward right lug.

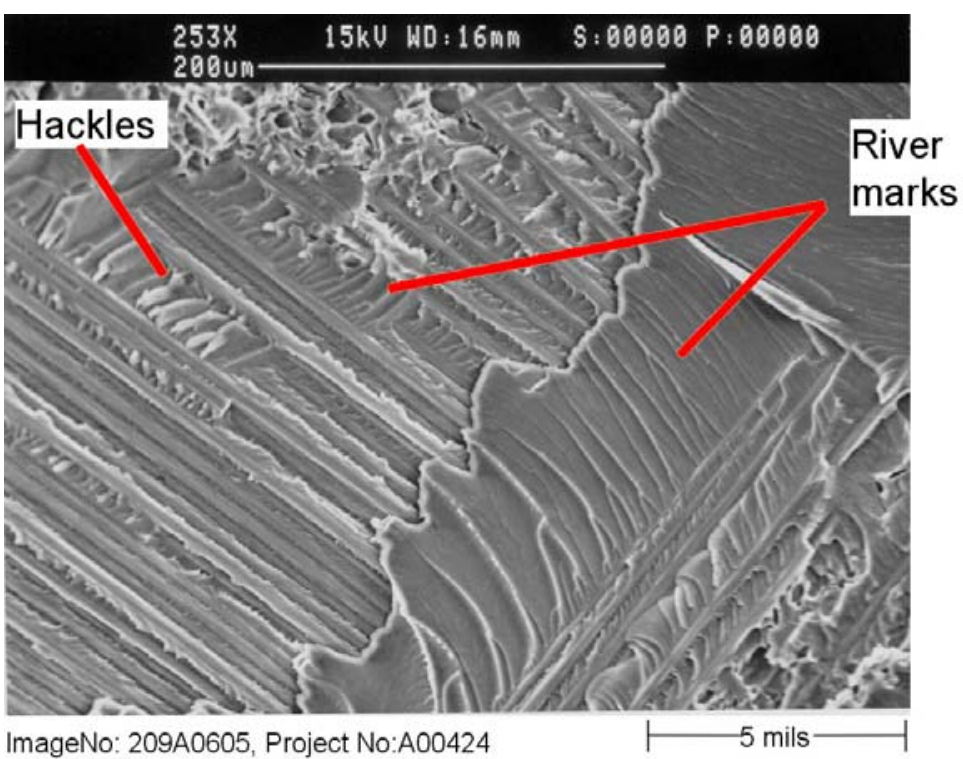

Figure 8. Delamination fracture features. 


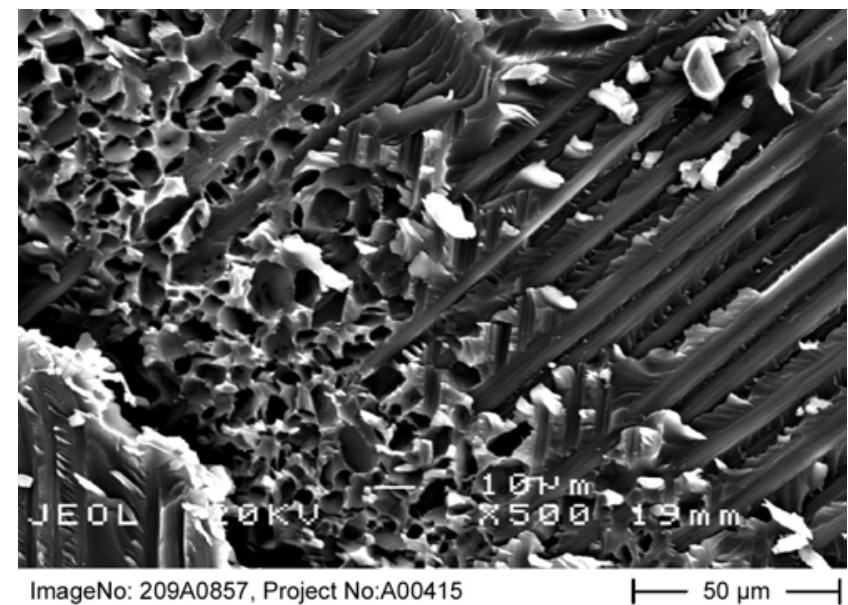

Figure 9. Porosity in matrix rich regions where bundles cross.

At the matrix-rich areas where bundles crossed, some porosity was observed having a somewhat angular appearance as shown in Figure 9. These pores were identified as arising from excess curing agent that had crystallized within the matrix. Such crystals could have been physically removed in the fracture process or dissolved by the water from which the vertical stabilizer was recovered.

On the delamination surfaces at the left forward lug, hackles on average pointed downward and forward on the outboard side of the delamination and upward and aft on the mating side, indicating a shear direction consistent with fracture under tensile loading and/or bending to the left. River patterns coalesced upward and aft, indicating crack propagation extending upward from the lower end.

On the delamination surfaces at the left aft lug, hackles on average pointed downward and forward on the side of the delamination associated with the

lug layers, and on average pointed upward and aft on the mating sides, consistent with the lug pieces moving downward relative to the remaining structure. In the portion of the delamination above the lug-to-skin transition, hackles generally pointed downward and forward on the outboard side and upward and aft on the mating side, indicating a shear direction consistent with fracture under bending to the left. River patterns generally coalesced upward and aft, indicating crack propagation extending upward from the lower end. No evidence of fatigue, such as striations in the matrix or edge rounding of the fiber ends on the translaminar fracture surfaces or matrix rollers or striations on the delamination surfaces, was observed on any of the fractures.

A summary of the observed fracture patterns is shown in Figure 10. The schematic drawing represents a horizontal cross-section of the vertical stabilizer through the main attachment lugs as viewed from above. Lug cross-sections with a light band at the center represent the lugs that failed through the bolt hole. Solid lug crosssections represent fractures above the bolt holes. Arrows on the lug surfaces indicate the approximate direction of fracture observed on the translaminar surface. On the left center lug, the area of compression fracture features near the outboard side is indicated. The results showed that the failure pattern of fracture in tension on the right side was consistent with an overall bending of the vertical stabilizer to the left. On the left side, the failure pattern of tension and bending to the left was consistent with an overall bending of the vertical stabilizer to the left after fracture of the lugs on the right side.

It was noted that the only compression translaminar failure features were present on the vertical stabilizer at the outboard side of the center aft lug. Typically, composites have less strength in compression than tension. However, the design of the vertical stabilizer was such that the magnitude of the lug failure loads in tension were less than in compression. Furthermore after failure of the lugs on the right side, the curvature of the panel would cause tension loading in the forward and aft lug and compression in the center lug with continued bending to the left. Other unknown factors, such as changes in air loading as the vertical stabilizer deflected after the initial fractures on the right side, would further influence the failure patterns on the left side.

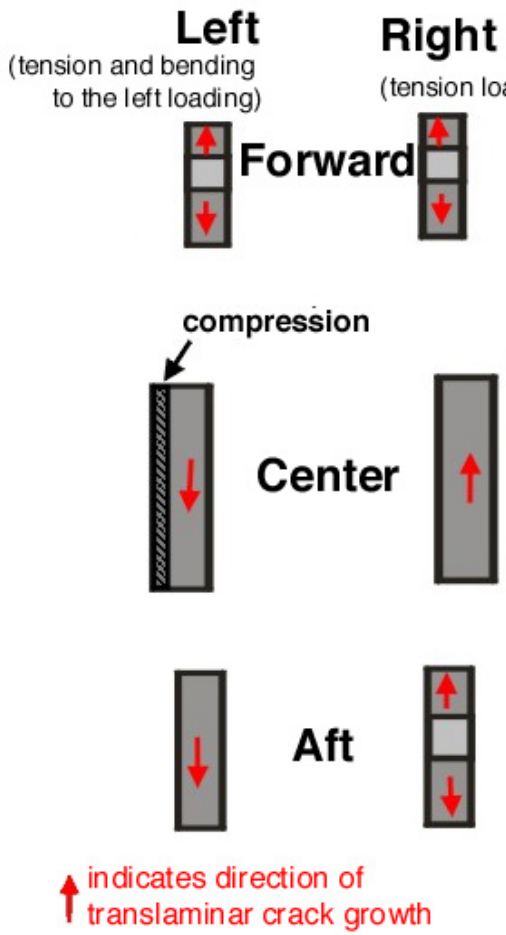

Figure 10. Main lug fracture pattern summary (viewed from above). 


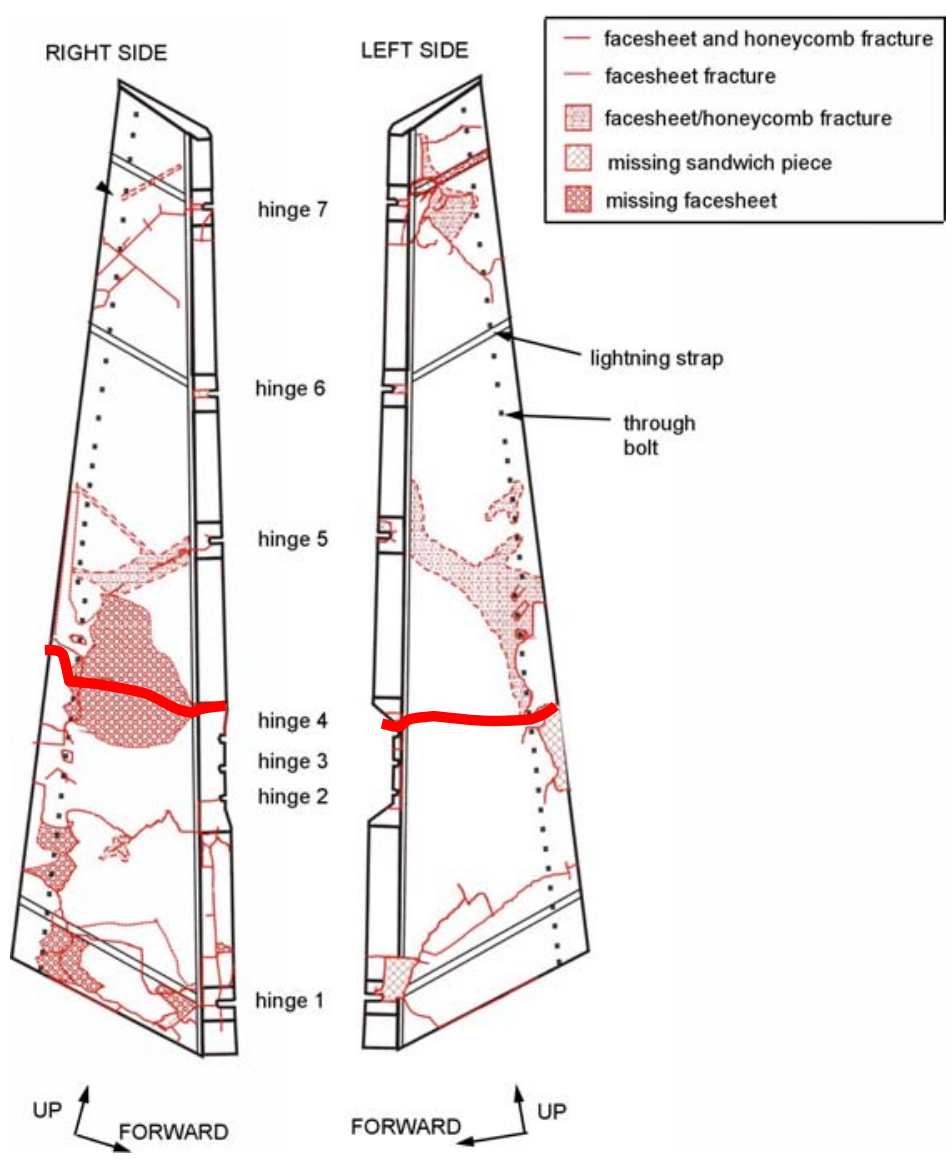

Figure 11. Rudder visible damage.

\section{Description of the rudder damage}

Approximately $95 \%$ of the rudder was recovered in numerous pieces. Two pieces of the rudder leading edge fairing and one piece of the rudder right skin panel were recovered on land. The remaining pieces of the rudder were recovered from Jamaica Bay. An overall view of the damage patterns on the rudder is shown in Figure 11. Detailed description of the visible damage is presented in reference 4. Results of NDI on the rudder are presented in reference 7 .

Many areas of the rudder had facesheets that fractured from the honeycomb core. The facesheet-to-honeycomb fractures had features consistent with laboratory peel test fracture features. A description of the laboratory peel tests is presented in reference 15. Metal strips at the leading and trailing edges of the skin panels had features consistent with overstress fracture with no evidence of fatigue.

All but one (the hinge 1 aft fitting) of the 14 rudder-to-stabilizer hinge fittings were recovered, either attached to the vertical stabilizer or to the rudder. Forward pieces of several fractured attachment bolts were not recovered. Hinge and attachment bolt fractures at the rudder hingeline were consistent with overstress fracture, and no evidence of fatigue was observed.

Portions of the rudder skin panels were examined using several NDI techniques including x-ray radiography, Lamb wave imaging, thermography, ultrasonic inspection, and tap testing. Generally, no evidence of debonding or water ingression was observed in areas away from visible fracture locations.

The rudder had a chordwise fracture through the skin panels on both sides of the rudder near hinge 4 as highlighted in Figure 11. The fractured facesheets of the honeycomb panels in this region were examined. The only fibers running perpendicular to the fractured surface were glass fibers in the adhesive layer that bonded the facesheet to the Nomex core. Chop marks indicating compression failure were found on some of the glass fibers on the inner and outer facesheet on the left side of the rudder and were also found on the inner facesheet on the right hand side. No compression markings were found on the outside facesheet of the right side. An explanation of how these failures occurred would be that the left side failed first due to a bending moment to the left. Once the left side failed the right side sandwich panel would carry the bending moment putting the inside facesheet in compression.

A large section of facesheet was peeled from the Nomex core in the area of hinges 2, 3, and 4. The facesheet was not recovered, but the fractured adhesive attached to honeycomb was examined and found to have step and scalloping features as seen in Figure 12 that indicated a fracture direction. River markings found in the scalloped region supported this interpretation of the

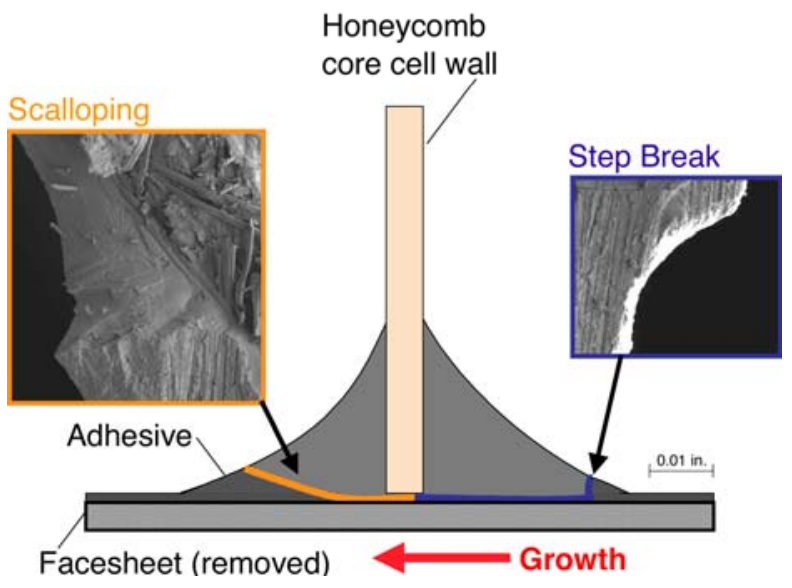

Figure 12. Fracture of the rudder honeycomb core from the facesheet. 
fracture growth direction. From samples taken from three separate regions, the facesheet appeared to have been peeled from the forward side of the rudder skin panel toward the trailing edge.

In summary, no evidence of significant preexisting damage was observed on the rudder. Furthermore, airplane performance analysis based on information from the flight data recorder showed the rudder performed as expected until the vertical stabilizer separated from the fuselage. Also, a structural analysis showed that the aerodynamic loads on the rudder prior to separation of the vertical stabilizer from the fuselage were insufficient to cause failure. Therefore, damage to the rudder was considered secondary to the failure of the vertical stabilizer.

\section{Subcomponent Tests}

Structural analysis indicated that under accident loading conditions, fracture of the vertical stabilizer would have intitated at the right aft lug. Three aft lugs were obtained for mechanical testing using applied loads that were derived from recorded flight data from the accident. The lug for the first test was obtained from a production left skin panel that had sections cut from it for destructive testing, but the aft lug had been left undisturbed. The lugs for the second and third tests were obtained from a vertical stabilizer that had been removed from service after experiencing loads exceeding design limit loads. The three vertical stabilizer aft lug specimens were tested at Airbus Industrie under National Transportation Safety Board supervision in a loading fixture that applied prescribed forces and moments to the lugs. Testing of each lug continued until a translaminar fracture was observed. The fracture loads for these three tests were consistent with calculated accident loads and with earlier tests completed by Airbus Industrie during certification. Details of the test procedures and results are documented in references 16-20. A fractographic examination of each of the lugs was conducted after completing the tests as documented in reference 21 .

Before testing, each lug was examined for non-visible defects or damage using ultrasonic inspection. Results of these inspections are documented in reference 21. No defects were observed in the first test lug. Some damage was detected in each of the second and third test lugs near the lug attachment hole and in some areas in the lug fitting assembly transition area above the lowermost rib, however these lugs had experienced in-service loads exceeding design limit loads. Following the tests, the lugs were examined again using ultrasonic inspection. The post-testing ultrasonic inspection showed that the preexisting damage in these lugs grew in size during the testing.

Overall views of the lugs from each test are shown in Figure 13 (outboard surface view). A similar view of the accident right aft lug also is shown in Figure 13. Unlabeled red arrows indicate where translaminar fractures intersected the outboard surfaces of the lugs, and an unlabeled large green arrow indicates loading direction (the force vector for the horizontal and vertical loading components for each lug). The lugs from the first and second tests were left aft lugs, and as such, the orientations are mirror images of the accident right aft lug and the third test lug.

Results from the fractographic

examination showed that fractures in the test lugs occurred at locations similar to those on the accident right aft lug. In the first test, loading was interrupted after fracture occurred as shown in Figure 13. The translaminar fracture was located at a position on the forward part of the lug in a plane nearly parallel to the resultant
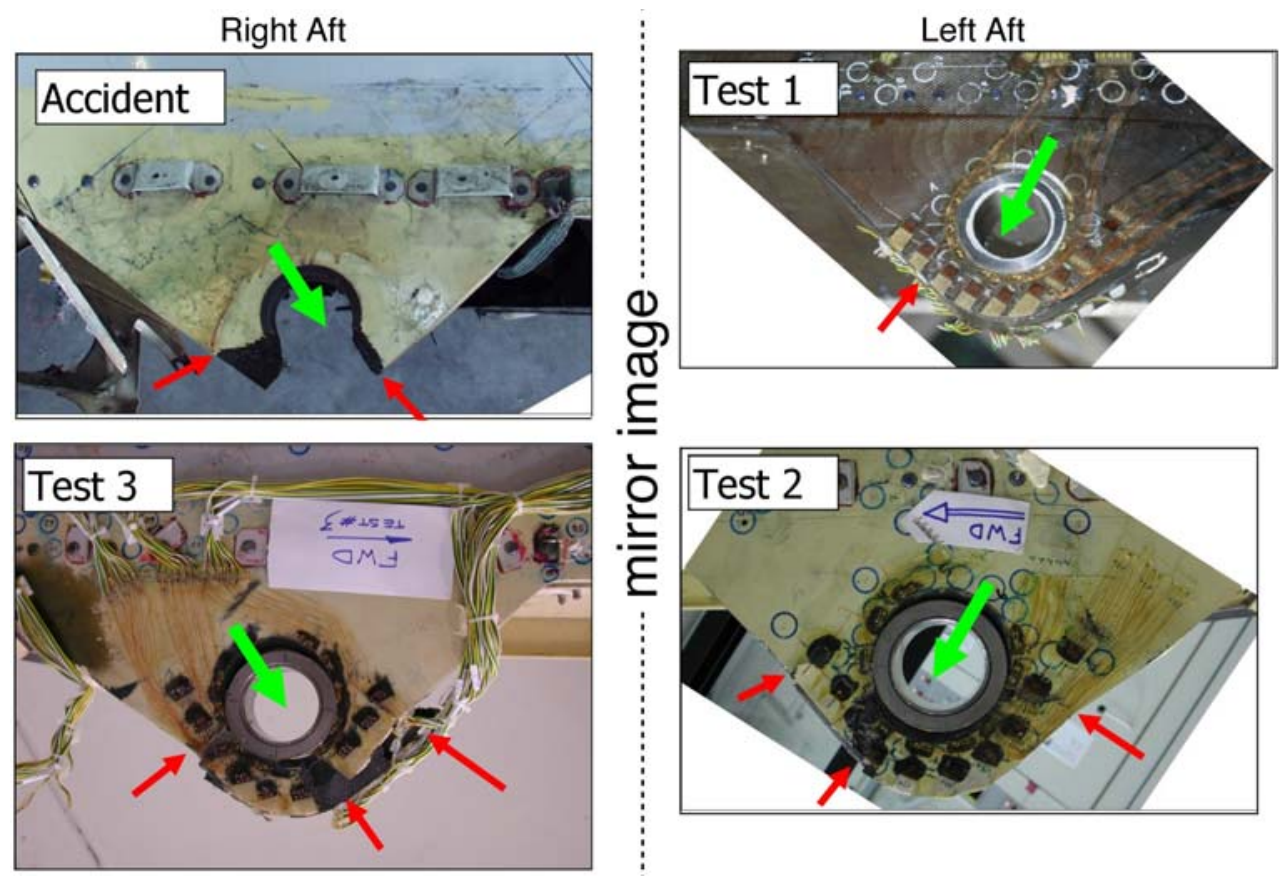

Figure 13. Aft lugs from accident and subsequent subcomponent tests. 
force direction, similar to one of the translaminar fractures in the accident right aft lug. Fracture features for the lugs from tests 2 and 3 were similar to each other. The outboard side of each of these lugs had a translaminar fracture on the forward sides of the holes in a plane nearly parallel to the loading direction and another translaminar fracture at the aft side of the hole in a plane approximately perpendicular to the loading direction, fractures similar to that of the accident lug. In addition on the outboard sides, a compression buckling fracture was observed on the forward sides of each lug above the fracture parallel to the loading direction, which is different from features on the accident lug but was attributed to constraints of the loading fixture. On the inboard sides of lugs 2 and 3, fracture locations were on translaminar planes different from that of the outboard side of the lug. This change in fracture planes was similar to that of the accident right aft lug.

A delamination was present within the first test lug having an extent similar to that of the accident right aft lug and in a location through the thickness slightly outboard of that of the accident right aft lug. Delaminations also were detected above the translaminar fractures in lugs 2 and 3. In lugs from tests 2 and 3, the locations of the delaminations through the thickness were similar to that of the accident right aft lug, but the extents of the delaminations in the test lugs were slightly less.

Each subcomponent test lug had translaminar fractures that intersected the lug hole and had delaminations that were located within the lug, features similar to the accident right aft lug. Each lug had a translaminar fracture at the forward lower side of the hole on the outboard side of the lug, including the first test, which was interrupted and had no other translaminar fractures. The fracture at the forward lower side of the hole corresponds to one of the translaminar fracture locations on the accident lug. The second test lug showed changes in translaminar fracture planes that were qualitatively similar to that of the accident right aft lug. These results indicated that the accident right aft lug had fracture features consistent with being the first lug fracture from a substantially intact vertical stabilizer and rudder under accident load conditions.

\section{Concluding Remarks}

The fractographic examination revealed no evidence of pre-existing damage or fatigue cracking in the vertical stabilizer or rudder, supporting the conclusion that the separation of the vertical stabilizer and rudder was a result of high aerodynamic loads. The fractographic results of examination of the main attachment lugs for the vertical stabilizer showed that failures on the right side of the vertical stabilizer were overstress failures under tension loading, consistent with an overall bending of the vertical stabilizer to the left. Fractographic results for the main lugs on the left side of the vertical stabilizer showed overstress failure in tension and bending to the left, consistent with bending of the vertical stabilizer to the left after failure of the main lugs on the right side. The structural analysis of the vertical stabilizer and rudder also conducted as part of the overall investigation indicated that under accident loads, fracture of the vertical stabilizer would initiate at the right aft main lug, which was consistent with the fractographic analysis.

The failure mode in the accident was further confirmed by a series of three aft lug subcomponent tests. The failure loads for these three tests were consistent with predicted failure loads and with earlier tests completed by Airbus Industrie during certification. Fracture patterns for the three test specimens were compared to the corresponding structure on the accident airplane, and good correlation was observed.

The analysis of the fractographic evidence was incorporated into the overall analysis of the accident. As a result of the analysis of the facts learned during the course of the nearly 3-year long investigation of the accident, the Safety Board determined that the probable cause of the accident was, "the in-flight separation of the vertical stabilizer as a result of the loads beyond ultimate design that were created by the first officer's unnecessary and excessive rudder pedal inputs. Contributing to these rudder pedal inputs were characteristics of the Airbus A300600 rudder system design and elements of the American Airlines Advanced Aircraft Maneuvering Program ${ }^{22}$."

\section{References}

${ }^{1}$ Mills, K., et.al., ed. Fractography, ASM Handbook Vol. 12. 1987, ASM International: Metals Park, Ohio.

${ }^{2}$ Kar, R.J., Atlas of Fractographs, in Composite Failure Analysis Handbook Volume 2: Technical Handbook. 1992, Northrop Corp, Aircraft Div.

${ }^{3}$ Sjögren, A., L.E. Asp, and E.S. Greenhalgh, Interlaminar Crack Propagation in CFRP: Effects of Temperature and Loading Conditions on Fracture Morphology and Toughness, in Composite Materials: Testing and Design, and Acceptance Criteria, ASTM STP 1416, Nettles and Zureick, Editors. 2002.

${ }^{4}$ NTSB, Materials Laboratory Factual Report 02-077, NTSB Public Docket, 2002.

${ }^{5}$ NTSB, Materials Laboratory Factual Report 02-083, NTSB Public Docket, 2002.

${ }^{6}$ NTSB, Materials Laboratory Factual Report 03-018, NTSB Public Docket, 2003.

${ }^{7}$ NTSB, Materials Laboratory Factual Report 02-078, NTSB Public Docket, 2002. 
${ }^{8}$ NTSB, Materials Laboratory Factual Report 03-033, NTSB Public Docket, 2003.

${ }^{9}$ Purslow, D., Matrix Fractography Of Fibre-Reinforced Thermoplastics, Part 2. Shear Failures. Composites Vol. 19, 1988.

${ }^{10}$ Stumpff, P.L., Fractography, in ASM Handbook, Vol. 21: Composites. 2001. p. 977-987.

${ }^{11}$ Stumpff, P.L., personal communication. 2002.

${ }^{12}$ Mandell, J.F., Fatigue Behavior of Short Fiber Composite Materials, in Fatigue and Fracture of Composite Materials, K.L. Reifsnider, Editor. 1990, Elsevier. p. 231-337.

${ }^{13}$ Singh, S. and E. Greenhalgh. Micromechanisms of Interlaminar Fracture in Carbon-Epoxy Composites at Multidirectional Ply Interfaces. in 4th International Conference on Deformation \& Fracture of Composites. 1998. Manchester, UK: UMIST.

${ }^{14}$ Hibbs, M.F. and W.L. Bradley, Correlations Between Micromechanical Failure Processes and the Delamination Toughness of Graphite/Epoxy Systems, in Fractography of Modern Engineering Materials: Composites and Metals, ASTM STP 948, J.E. Masters and J.J. Au, Editors. 1987, American Society for Testing and Materials: Philadelphia. p. 68-97.

${ }^{15}$ NTSB, Materials Laboratory Factual Report 02-082, NTSB Public Docket, 2002.

${ }^{16}$ NTSB, Structures 7 Addendum 17, Airbus Report, Flight AA587 Structure Accident Investigation, Validation of Subcomponent Test Principles, NTSB Public Docket, 2004.

${ }^{17}$ NTSB, Structures 7 Addendum 16, Airbus Report, AAL587 Airbus Structure Investigation, Lug Test\#3 - Results Test/FEA Comparison, NTSB Public Docket, 2004.

${ }^{18}$ NTSB, Structures 7 Addendum 15, Airbus Report, AAL587 Airbus Structure Investigation, Lug Test\#2 - Results Test/FEA Comparison, NTSB Public Docket, 2004.

${ }^{19}$ NTSB, Structures 7 Addendum 8C, NASA Report NASA/TMX-2003-XXX, Structural Analysis Report on the American Airlines Flight 587 Accident - Part 3, NTSB Public Docket, 2003.

${ }^{20}$ NTSB, Structures 7 Addendum 6 (Rev A), Airbus Report, AAL587 Airbus Structure Investigation, Lug sub-component test \#1 -Results Test/FEA Comparison, NTSB Public Docket, 2003.

${ }^{21}$ NTSB, Materials Laboratory Factual Report 04-065, NTSB Public Docket, 2004.

${ }^{22}$ NTSB, Aircraft Accident Report, In-Flight Separation of Vertical Stabilizer, American Airlines Flight 587, Airbus Industrie A300-605R, N14053, Belle Harbor, New York, November 12, 2001, NTSB/AAR-04/04, 2004. 